\section{Blood Glucose in Crayfishes in Relation to Moult and Handling}

During a recent investigation of the physiology of excretion in the crayfish ${ }^{1}$, it was discovered that significant differences in blood glucose-levels existed between intermoult (stage $C$ ) and premoult (stage $D$ ) specimens of Pacifastacus leniusculus (Dana) (Table 1). The moult stage was determined by a modification of the method of Drach ${ }^{2}$. The crayfishes were kept in a water-bath at $16^{\circ} \mathrm{C}$. in which they had been unsegregated and unfed for periods of one to two weeks. Blood glucose was determined by the glucose oxidase (enzymatic) method of Saifer and Gerstenfeld ${ }^{3}$ (for details of experimental procedure, see Riegel and Kirschner, ref. 1).

Table 1. Blood Glucose-levels of Intermodlt $(C)$ and Premoult (D) Male Pacifast VHRY SIGNIRICANT $(t=3.06 ; P=<1$ PER CENT)

\begin{tabular}{|l|c|c|}
\hline \multicolumn{1}{|c|}{ Moult stage } & $C$ & $D$ \\
\hline Number & 10 & 9 \\
Average blood glucose (mgm. per cent) & 21 & 48 \\
Range & $(5-39)$ & $(18-91)$ \\
Standard error & $3 \cdot 3$ & $7 \cdot 7$ \\
\hline
\end{tabular}

Glucose proved to be a highly mobile substance in crayfish blood ; injected glucose disappeared rapidly. Handling of crayfishes (for example, injection of materials, and especially withdrawal of blood samples at frequent intervals) commonly resulted in a spontaneous rise in blood glucose-levels, a prolonged cessation or marked decrease in urine production, and in many cases the abnormal appearance of glucose in the urine.

The results of determinations of normal blood glucose-levels of $C$ - and $D$-stage crayfishes agree with those of Renaud ${ }^{4}$, who measured the reducing value of the blood of Cancer pagurus. However, Scheer ${ }^{5}$ found no difference in blood carbohydrate-level between late $C$ - and early $D$-stage Carcinides (= Car cinus) maenas. Similarly, McWhinnie and Scheer ${ }^{6}$ found that the blood glucose-levels of Hemigrapsus nudus reached their maximum during the intermoult (C) stage of the moult-cycle and actually declined during the premoult $(D)$ stage. McWhinnie and Scheer determined glucose by a method similar in most respects to that used in the present work. They found that glucose comprised less than 20 per cent of the total 'blood sugar' value determined by other less. specific methods.

The reasons for the spontaneous rise in blood glucose of handled crayfishes are obscure. It seems reasonable to assume that handling placed the crayfishes under stress. Since an elevation of blood glucose-levels is a common stress phenomenon seen in vertebrates, it is possible that a similar stress-blood glucose relationship exists in the crayfish. This explanation would fail, if the view of Scheer ${ }^{7}$, that glucose is not utilized as a substrate for oxidative metabolism in Crustacea, is accepted. However, more recent evidence (ref. 8 and Scheer, B. T., personal communication) indicates that glucose is, in fact, utilized for oxidative metabolism in crustaceans; at least, according to Scheer ${ }^{7}$, in those crustaceans that undergo a period of dormancy during their moult eycle (anecdysis). The crayfish is an anecdytic form, as are the crabs, Hemigrapsus nudus and Carcinides maenas.
The complete cessation or marked decrease in urine production and the glucosuria of crayfishes that were handled ${ }^{1}$ is suggestive of a hormonal effect. For example, the stoppage or decrease in urine production commonly was maintained for $20 \mathrm{hr}$. or more during the experimental periods-long after handling had ceased. Further, it was only after 20 $\mathrm{hr}$. that glucosuria occurred. It is well known that the sinus glands of Crustacea contain a diabetogenic hormone, which is reported to be responsible for most of the hyperglycæmic effects seen in those animals? The diabetogenic hormone conceivably could be responsible for the hyperglyexmia and possibly the glucosuria of handled crayfishes. Further, it is possible that it, or some as yet unknown hormone fraction, has an antidiuretic effect in the crayfish.

This work was supported by funds provided for medical and biological research by the State of Washington Initiative No. 171, and by a grant $(G 4925)$ to L. B. Kirschner from the National Science Foundation.

Department of Zoology, J. A. RIEGEL* Washington State University,

Pullman, Washington.

* Postdoctoral Research Fellow of the National Heart Institute, National Institutes of Health.

${ }^{1}$ Riegel, J. A., and Kirschner, L. B., Biol. Bull. (in the press).

${ }^{2}$ Drach, P., Ann. Inst. Océanog. Monaco, 19, 103 (1939).

${ }^{3}$ Saifer, A., and Gerstenfeld, S., J. Lab. and Clin. Med., 51, 448 (1958).

4 Renaud, L., Ann. Inst. Océanog. Monaco, 24, 259 (1949).

5 Scheer, B. T., Biol. Bull., 116, 175 (1959).

- McWhinnie, M. A., and Scheer, B. T., Science. 128, 90 (1958).

"Schecr, B. T., "Recent Advances in Invertebrate Physiology", 213 (University of Oregon Pub., 1957).

${ }^{8}$ Hu, A. S. L., Arch. Biochem. Biophys., 75, 387 (1958).

-Kleinholz, L. H., Havel, V. J., and Reichart, R., Biol. Bull., 99 $454(1950)$.

\section{Membrane Potential Changes associated with Stimulation of Smooth Muscle by Adrenalin}

THE smooth muscle of the taenia coli of the guinea pig is contracted by acetylcholine and is relaxed by adrenalin. It has been shown that acetylcholine contraction is associated with depolarization of the muscle membrane and initiation or increase in spike activity $^{1,2}$. Adrenalin relaxation is associated with hyperpolarization of the membrane and inhibition of spike activity ${ }^{1,3}$.

The smooth muscle of the muscularis mucose (dog) is contracted by both acetylcholine and adrena$\mathrm{lin}^{4}$. It was of interest, therefore, to observe whether adrenalin contraction of this muscle was associated with hyperpolarization or depolarization.

Membrane potential changes of muscularis mucosie (pig cesophagus) in the presence of adrenalin and acetylcholine were measured by the sucrose gap technique ${ }^{5}$. Fig. 1 shows that contraction by adrenalin as well as by acetylcholine was associated with depolarization and initiation of spike activity.

This result supports the view that drugs act via a membrane system, where depolarization and initiation of spike activity result in contraction, and hyperpolarization in relaxation. It is unlikely that adrenalin acts in two completely different ways on the muscle membranes of the taenia coli and museularis mucosw. It is more likely that adrenalin acts in the same way on two muscles which differ in internal/external ion distribution and/or in membrane permeability properties. Comparison of the morphological features 